\title{
The Mutable Nature of Risk and Acceptability: A Hybrid Risk Governance Framework
}

\author{
Catherine Mei Ling Wong*
}

\begin{abstract}
This article focuses on the fluid nature of risk problems and the challenges it presents to establishing acceptability in risk governance. It introduces an actor-network theory (ANT) perspective as a way to deal with the mutable nature of risk controversies and the configuration of stakeholders. To translate this into a practicable framework, the article proposes a hybrid risk governance framework that combines ANT with integrative risk governance, deliberative democracy, and responsive regulation. This addresses a number of the limitations in existing risk governance models, including: (1) the lack of more substantive public participation throughout the lifecycle of a project; (2) hijacking of deliberative forums by particular groups; and (3) the treatment of risk problems and their associated stakeholders as immutable entities. The framework constitutes a five-stage process of co-selection, codesign, co-planning, and co-regulation to facilitate the co-production of collective interests and knowledge, build capacities, and strengthen accountability in the process. The aims of this article are twofold: conceptually, it introduces a framework of risk governance that accounts for the mutable nature of risk problems and configuration of stakeholders. In practice, this article offers risk managers and practitioners of risk governance a set of procedures with which to operationalize this conceptual approach to risk and stakeholder engagement.
\end{abstract}

KEY WORDS: Actor-network theory; deliberative democracy; responsive regulation; risk governance

\section{INTRODUCTION: THE PROBLEM WITH RISK AND ACCEPTABILITY}

Before the Fukushima disaster in March 2011, nuclear power was scarcely considered a controversial issue in Japan and beyond. Indeed, it was upheld as a key source of clean, nonemitting energy, supplying $30 \%$ of Japan's electricity needs. Its risks were largely accepted, or at least un-debated in the public sphere. This changed drastically in the wake of the disaster, with tens of thousands taking to the streets in protest against government plans to restart some of its nuclear reactors. ${ }^{(1)}$ Two years on, protest dwindled to a mere 200 when a local governor approved the resumption of two reactors in the Sendai power stations. In fact, the residents

*Address correspondence to Catherine Mei Ling Wong, Cairns Institute, James Cook University, Townsville City, QLD 4811, Australia; catherine.wong@jcu.edu.au. of Satsumasendai hosting the nuclear power plants voted yes to restarting the reactors. ${ }^{(2)}$ Whether this is a reflection of the ebb and flow of public sentiment in catastrophic risk events or an indication of actual improvements to risk governance in the industry, this underscores the mutable nature of risk problems and their acceptability.

Reflecting on this mutable ${ }^{1}$ nature of risk, this article explores what the implications are for risk

\footnotetext{
${ }^{1}$ This means that the objects, people, ideas, narratives, etc. that constitute a risk problem are not stable but fluid and ever changing. This draws on Latour's (1987) concept of "immutable mobiles," which are objects like maps, photos, diagrams, etc. that can be easily transportable (i.e. mobile) without changing the original characteristics of the things/ideas they represent. This concept of mutability has since been expanded and applied to the conceptualization of power and organizations as emergent network effects that are unstable and need constant reenactment to maintain the semblance of stability (see, for example, Law ${ }^{(3)}$ and Alcadipani and Hassard $\left.{ }^{(4)}\right)$. This article applies this idea of "mutability" to
} 
governance in practice, guided by two interrelated conceptual and practical questions: How can risk governance deal with the mutable character of risk problems and acceptability? How does this change public participation in risk governance in practice?

Deeply connected to this is the problem of what constitutes acceptable risk and how stakeholders might arrive at an agreement. Typically dominated by technical perspectives,${ }^{(6)}$ it is often the assumption in the risk analysis literature that better data lead to better decisions on what is an acceptable level of risk. The long history of risk controversies from biotechnology and industrial accidents to climate change, however, show that better technical risk assessment alone neither prevents disasters nor translates into public acceptability. Even the experts disagree; actors are fluid; conditions variable; and social, ecological, and technological systems increasingly interconnected. Indeed, risk acceptability is less about more accurate probabilities than it is about subjective values and the perception of distributive justice. ${ }^{(7)}$ More reliable technical data also cannot address weak safety cultures; ${ }^{(8)}$ the pressures of treadmill production ${ }^{(9)}$ to cut corners and prioritize production over maintenance; and the ways in which organizational cultures filter information and skew so-called objective decision making. ${ }^{(10)}$

Risk governance attempts to address some of these limitations by integrating the public into decision-making processes. In doing so, the scope of risk assessment is widened to account for societal values in decisions about risk, thereby also increasing the likelihood of public acceptability. Accountability is not just a one-way communication of data to the public but about procedural fairness, social learning, and mechanisms for lay interrogation, which not only enhances public trust, but also improves the quality of technical assessment. ${ }^{(11)}$ Major contributions have come from integrative risk governance, ${ }^{(7,12)}$ deliberative democracy, ${ }^{(13,14)}$ and the related subfield of smart/responsive regulation. ${ }^{(15-17)}$

These perspectives offer valuable insights to how public participation can produce better risk decisions, but face a number of conceptual and practical limitations. Firstly, public participation remains limited to preimplementation framing of the problem and preestimating risks largely aimed at establishing political legitimacy. The actual work of planning, monitoring, and managing risk in the con-

the analysis of risk problems and the organization of risk governance in practice. struction and operation phases of a project ${ }^{2}$ remains the prerogative of technical experts. Existing risk governance models, therefore, offer few institutional arrangements and coordination mechanisms that facilitate public involvement in risk monitoring and management throughout the lifecycle of a project.

This is problematic because production pressures influence decisions on timelines, maintenance, and safety; organizational cultures interfere with safety cultures; regulatory capture seeps in; and technical experts are constrained by incomplete data. These sources of more mundane risks (e.g., routine (over)release of pollutants into the environment, underreporting of incidents, ignoring warning signals, etc.) ultimately contribute to catastrophic risk events (e.g., industrial accidents like the Deepwater Horizon oil spill in 2010; epidemics like the mad cow disease outbreak in the United Kingdom in 1987 and the swine flu in 2009; or a combination of natural and industrial disasters as seen in the Fukushima nuclear disaster). ${ }^{(18)}$ Public participation, therefore, is necessary not just for the purpose of preimplementation legitimacy but postimplementation accountability throughout the lifespan of a project. As Wynne ${ }^{(19)}$ notes, companies are trusted as long as they are well policed. Greater public participation in the policing of industries, therefore, has the double benefit of reducing risks and enhancing public trust.

Secondly, risks and benefits tend to be treated as mutually exclusive, which reduces discussions on acceptability to a measure of what is the "right" level of risk-benefit tradeoffs and the acceptable amount of compensation for the "losers." 3 This overshadows other discussions that explore ways to generate more positive impacts of change for all stakeholders. ${ }^{(18)}$ Public deliberation, therefore, needs to go beyond a narrow focus on minimizing risks and trading them off with narrowly defined (monetary) benefits to include maximizing benefits in ways that can build (local) capacities and enhance resilience to risks.

\footnotetext{
${ }^{2}$ This article uses "projects" as the context in which risk governance activities occur. These are development projects that often involve the application of science and technology and pose social and environmental risks.

${ }^{3}$ This mode of thinking is increasingly gaining traction even in the business world. Porter and Kramer's ${ }^{(20)}$ concept of "shared values," first published in Harvard Business Review, 2011, presents a shift in business thinking away from business vs. society tradeoffs towards policies and operating practices that enhance the competitiveness of a company while simultaneously advancing the economic and social conditions in the communities in which it operates.
} 
Finally, existing models generally treat risk problems and the configuration of affected parties/stakeholders as immutable entities. Efforts are, therefore, aimed at pinning down a definition of the problem and locking in arrangements with a fixed set of stakeholders/representatives. Risk problems are, however, more often than not, mutable entities: stakeholders drop out and new ones join in along with new sets of concerns and interests; old claims are displaced by new knowledge; technologies evolve; ecological systems intervene; and new laws get drafted or old ones are invoked more actively by new entrants. Current risk governance frameworks are ill-equipped to deal with this ever-changing configuration of actors (human and nonhuman) in a risk problem. While it is well established in the literature that the acceptability of risk is subjective and variable from person to person, the challenge remains as to how such variabilities can be accounted for in the practice of risk governance.

To address these challenges, this article introduces an ANT perspective on risk governance whereby risk problems and acceptability are conceived as unstable network effects. This conceptual modification is then translated into a hybrid risk governance framework that practitioners in risk governance (i.e., regulators, consultants, risk managers, conflict mediators, researchers, etc.) can use. The aims of this article are twofold: conceptually, it proposes a framework of risk governance that accounts for the mutable nature of risk problems and the configuration of stakeholders. In practice, this article offers risk managers and practitioners of risk governance a set of procedures with which to operationalize this reconceptualization of risk and better integrate affected publics in decision-making processes.

The model proposed here is based on a larger empirical study on nuclear power in India after the Fukushima disaster, and is thus most relevant to that industry. ${ }^{(21)}$ But it is also applicable to a wide range of industrial sectors such as the mining and energy industries, manufacturing, agribusinesses, etc., where operations pose both mundane social and environmental risks that can lead to catastrophic risk events. The model is also targeted at developing countries, where industrial development is still growing rapidly and institutions of governance and public participation are still relatively weak. Ideally, the model should be applied to projects that are in the conceptual/planning stage, but it can also be used in cases where projects have already been implemented but are facing significant public/local resistance.

\section{RISK GOVERNANCE AND THE ROLE OF PUBLIC PARTICIPATION}

\subsection{The Adaptive and Integrative Model}

The concept of risk governance is concerned with a wide range of actors, institutions, political cultures, processes, and mechanisms that influence how risk information is collected, analyzed, and communicated. Importantly, it seeks to create a set of arrangements in which decisions on risk can be made collaboratively and in coordination between multiple stakeholders. ${ }^{(7)}$ The "adaptive and integrative model" developed by Renn and colleagues ${ }^{(12,22,23)}$ attempts to address risk acceptability by integrating both realist and constructivist perspectives in risk governance. This combines scientific analysis by technical experts with stakeholder and public inputs at varying degrees depending on the type of risk problem: complex, uncertain, ambiguous, or a combination of all. (24) Public participation starts early in a project's lifecycle at the "preestimation" stage where risks are framed with a key objective of establishing a consensus on the "right" balance of risks and benefits; pros and cons. ${ }^{(12)}$ This gives political legitimacy to technical decisions on risk by reflecting public preferences, thus establishing acceptability.

This model, however, is limited in a number of ways. Firstly, the actual location of lay publics within the framework and the forms of participation still reflects a bias towards expert knowledge and formal organizations. Public input is limited to the discursive framing of the problem and choosing among options preselected for them by risk managers and technical experts who still dominate the process of risk estimation, evaluation, and management. ${ }^{(25)}$ The main work of knowledge production is still largely monopolized by technical experts and lay/local expert knowledge tends to be marginal or underutilized after a project commences. This privileging of expert knowledge is problematic because it narrows the scope of analysis, estimations of risk, and the general conceptualization of what falls within the realm of possible hazards and impacts that is considered in risk analysis. The limited scope of public participation also lends itself to the perception that it is tokenistic and merely an add-on to decisionmaking processes, which in turn increases cynicism and distrust, ${ }^{(11)}$ ultimately undermining the goal of establishing legitimacy and acceptability.

Secondly, the inclusion of public interests largely takes the form of interdisciplinary representation 
by social scientists, economists, and formal organizations like NGOs. These participants are still experts in nontechnical fields of science, whereas involvement by directly affected but informally organized local/rural communities-i.e., affected publics-remains limited. Direct involvement by these stakeholders is important because they possess knowledge of the local environment and management strategies that have been developed and adapted over generations. Such forms of knowledge may fall outside formal scientific intellectual frameworks but can ultimately prove to be more effective and useful when applied to the local context. ${ }^{(26)}$

\subsection{Deliberative Democracy}

Deliberative democracy, like the "adaptive and integrative model," is concerned with collective choice mechanisms such as deliberative polls, citizen's juries, planning cells, and consensus forums collectives that Renn categorizes into "pools of instruments." $(13,24)$ But deliberative democracy deviates from Renn's model in three significant ways. Firstly, less importance is placed on establishing a consensus on the definition of risk than on the processes that enable collective interests and shared values to emerge. The function of deliberative platforms, therefore, is to discover new procedures, techniques, concepts, and institutions that can be used to pull the social together in whatever (unstable) form they may take. ${ }^{(27)}$ Discursive representation is a concept Dryzek et al. ${ }^{(28)}$ introduce to ensure that all relevant (and especially marginal) discourses are represented using a variety of methods, including random selection, the Q method, in-depth interviews, and focus groups.

Secondly, lay publics play a more central role in knowledge production. Conceptually, public participation is not limited to framing of the problem but is deeply embedded within project development processes from analyzing impacts and proposing alternatives, to monitoring planned interventions. Emphasis is also on empowering affected communities through capacity building, and developing social capital (e.g., social networks and trust) in the process. ${ }^{(29)}$ Finally, the physical and social dimensions of risk are treated as processes that are inextricably linked in what Dryzek ${ }^{(14)}$ calls "ecological intersubjectivity." The human and nonhuman worlds, social and natural systems, ecological and social wellbeing are, therefore, treated as mutually embedded in the assessment of risks and potential impacts.
Deliberative approaches, however, face a number of challenges in practice. Without proper implementation, deliberative processes can be hijacked by lobby groups or those with strongly held views. ${ }^{(30)}$ This can stifle discussions and skew outcomes in favor of specific group interests at the expense of the wider social good. The demands of certain lobby groups may also not be aligned with the common good and scuttle genuine attempts at engaging local communities. ${ }^{(11)}$ Indeed, Dryzek and Niemeyer ${ }^{(28)}$ acknowledge that strong lobby groups with larger membership may distort the representation of discourses but offer no strategies for how this can be mitigated. There is also a lack of practicable tools and concrete processes through which the ideals of deliberation can be incorporated into existing risk governance arrangements. Overall, critics of deliberative approaches argue that, done improperly, deliberation may instead exacerbate risk levels, introduce inefficiencies, stabilize unequal power relations, and produce trivial results. ${ }^{(24,31)}$ This article acknowledges these limitations, but contends that steps can be taken to circumvent them (see Section 3).

\subsection{Smart/Responsive Regulation}

Smart/responsive regulation is not often associated with risk governance, but presents particular insights to alternative ways for establishing accountability by industry vis-à-vis the regulatory process. It contends that simple state-market and regulationderegulation dichotomies inhibit attempts to find solutions that draw on the best of both approaches. Indeed, industries, it argues, can be effective (commercial) "third parties" in self-regulation ${ }^{4}$ through a mix of supportive mechanisms that enable and empower them to set their own standards and achieve them, while maintaining state regulatory agencies' authority to impose sanctions if they fail to solve the problem or produce the desired goals. ${ }^{(15,17)}$ Supportive mechanisms are crucial and can include co-regulation, environmental audits, liability rules for banks and insurers, environmental reporting, community right-to-know legislation, deliberative processes, and good neighbor agreements. ${ }^{(32)}$ Importantly, smart regulation relies significantly on wider industry peer pressure to ensure companies comply with standards

\footnotetext{
${ }^{4}$ It is important to note that "self-regulation" refers to the process by which an organized group regulates the behaviour of its members and not to an individual firm or company regulating itself. ${ }^{(32)}$
} 
and norms, and the ability of regulators and industry to jointly negotiate targets and strategies and provide external verification. Regulation is, thus, a responsive process, providing freedoms to industry to negotiate targets and achieve them, rewarding good performance with more incentives, but imposing state/legislative sanctions when targets are not met.

Examples have been cited in a number of cases, including the chemical industry's Responsible Care Programme; ${ }^{(33)}$ the Institute of Nuclear Power Operations (INPO) created by the nuclear industry in the United States after the Three Mile Island disaster; ${ }^{(34)}$ and the so-called KBS program started by the Swedish nuclear industry to deal with the problem of nuclear waste management. ${ }^{(35,36)}$ But even these successes are not immutable. Operators have resisted the use of "communitarian social control" by the INPO ${ }^{(34)}$ and the KBS is in constant negotiation with the public and state regulators to maintain conflict-free operation of nuclear activities.

Indeed, profit-driven industries are not naturally predisposed to regulate themselves and success depends on a wide range of supporting conditions, including an independent regulator with political clout, supportive legislation, an informed public, environmental feedback loops that threaten business sustainability, etc. Like deliberative democracy, proper implementation is crucial, which has proven complex in practice. Communication between the regulator and industry is key but prone to break down. Nielsen and Parker, ${ }^{(37)}$ for example, found in their study of anti-competition offenders in Australia that communication failed when different regulators dealt with the offender at different times in relation to different matters. Similar problems arose when different people within the business organization were communicating with the regulator at different stages and had different reactions that affected whether the business as whole changed its attitude and behavior. Self-regulation can also slow the pace of reform, as in the case of Australia's Retail Electronic Payment Systems, ${ }^{(38)}$ which was not properly tailored to the nature of the industry and was scuttled by overlapping regulatory functions between the Reserve Bank of Australia and the Australian Competition and Consumer Commission.

Nevertheless, smart regulation presents an alternative perspective on the source of accountability (which has implications for risk acceptability) and the role industries can play given the right incentives and institutional settings.

\subsection{ANT and Risk Governance}

ANT is not often associated with risk governance but offers new insights by reframing the function of deliberation, the organization of public participation, and the (mutable) nature of risk problems. From an ANT perspective, the acceptability of risk is itself mutable and participatory platforms are a loosely defined space where the configuration of participants is fluid and knowledge is incomplete. The function of deliberation, therefore, is to facilitate the co-production of knowledge, construct a community of shared fate, and create a pool of shared resources that all stakeholders can tap into to maximize benefits and minimize risks. Acceptability of risk by affected publics is produced by developing a project as a common enterprise that brings out the shared interests and identities of all stakeholders. This requires affected publics to be integrated into the full spectrum of risk governance activities, from risk estimation to monitoring and management.

Stakeholders are not predefined/selected by risk managers but are an emergent, heterogeneous congregation of "concerned groups." (39) This can include government regulators, industry (third parties), and affected lay publics - organized or otherwise. Stakeholder groups are also unstable entities, meaning their identities are problematic and their interests are the outcomes and not the causes of action itself. The function of participatory processes, therefore, is to steer discussions towards the production of shared discursive identities and interests. The reconfiguration of relevant stakeholders may also evolve over time. Participatory settings must, therefore, be flexible enough to allow new actors to join in and old ones to drop out.

Similarly, risk problems are conceived as mutable entities and risk acceptability is at best temporary and incomplete. The risk governance framework, therefore, must have a reflexive component that constantly reevaluates what the problems are, who the (new) stakeholders might be, and what their interests are. This approach favors adjustments and corrections as the project develops. Indeed, changes are not interpreted as dishonesty or unreliability, but an evolution/reconfiguration of the problem.

This naturally poses some challenges in practice. Most significantly, the success of such an approach requires a significant change in stakeholder attitudes towards accepting risk problems and their solutions as unstable and fluid in nature and translating that into practical measures. Communication between 
experts and lay persons is also difficult, often requiring a completely different way of thinking. Indeed, the emergence of science communication as a new field of study is indication of the enormity of this challenge. Callon's idea of concern groups emerging organically and then somehow organizing into a hybrid forum also overlooks barriers from preexisting institutions and bounded rationalities ${ }^{(40)}$ that prevent co-learning and co-production of knowledge, identities, and interests. Lastly, creating a framework that is flexible enough to deal with the mutable nature of risk problems and its stakeholders may also prove difficult. To date, no such framework exists. The concept of hybrid forums proposed by Callon and colleagues ${ }^{(39,41,42)}$ largely represents the ideals discussed above, but it remains more of a conceptual artifact without a comprehensive framework for how that may be implemented more systematically.

Nevertheless, ANT does offer the conceptual tools to deal with the mutable nature of risk problems, acceptability, and their configuration of actors. This reorganizes the priorities of deliberation; takes the pressure off forcing a consensus on fixed goals/definitions; and introduces new actors, knowledge, and mechanisms that can offer alternative solutions. The challenge is progressing from conceptual reframing to an actionable framework.

\section{A HYBRID RISK GOVERNANCE FRAMEWORK}

The proposed "hybrid risk governance framework" is named as such, drawing on Callon et al.'s(39) "hybrid forum" concept, but also to reflect the hybridization of ANT, integrative, deliberative, and responsive approaches to risk governance. The framework is not the answer to all the limitations cited in the previous section, but proposes some steps towards dealing with the four broad constrains in existing models: (1) limited public participation to representatives of formal organization such as NGOs, research institutions, social scientists, etc.; (2) hijacking by dominant/interest groups; (3) lack of mechanisms for public participation throughout the lifecycle of a project; and (4) the mutable character of risk problems and their associated stakeholders.

The framework, does two keys things differently: firstly, public participation is more than a process to legitimize a project. It is situated at the heart of decision making and knowledge production as means to expand the scope of information available to inform democratic debate; draw on local knowledge not privy to external experts; provide external monitoring; and better understand how public attitudes and perceptions are likely to shape responses (and resistance) to proposed change.(27) Including affected publics in decision-making processes, therefore, helps to solve many barriers to change, improve resilience, and ultimately produce better decision outcomes. Secondly, new participants are able to join in and old ones to drop out at each stage of deliberation in this model, thereby allowing for the configuration of stakeholders to shift and change as the problem evolves.

The framework is aimed at local-level implementation of development/industrial projects. The target participants and audiences are, therefore, local communities, local governments, and plant- or factory-level directors and senior managers (i.e., local branches of project proponents). This may require decentralizing decision making in the corporate structure and divesting autonomy to local operating plant directors to engage and negotiate with local communities on behalf of the parent company. This is both pragmatic and strategic for project proponents on two fronts: firstly, officials and managers at the local level have better knowledge of the unique conditions and contexts of the locale. Secondly, plant directors have greater vested interests in meaningful engagement with local communities than an executive in the headquarters as the success of their operations depends on it. Other institutional support may also be needed to incentivize or mandate the implementation of this framework. Some already exist in the form of legislated requirements for public consultation prior to project implementation and social impact assessments. ${ }^{5}$ But additional institutional pressure can come from the private sector such as the insurance industry by increasing premiums of companies that fail to demonstrate adequate public participation.

\footnotetext{
${ }^{5}$ India, for example, has a law that requires companies to conduct an environmental impact assessment to be approved by the Ministry of Environment and Forestry before any project can commence. Implementation, however, is weak, corruption is rife, and the social impacts poorly assessed. Under this framework, other laws such as the recently amended Land Acquisition Act passed in 2014 can be brought in to strengthen institutional governance. This amended law brings in stricter norms to land acquisitions and significantly increases landowners' compensation. It also specifies special protection to Scheduled Castes and Scheduled Tribes where additional compensation is mandated and the consent of the village council must be acquired for any land acquisition to be approved. ${ }^{(4)}$
} 
The framework consists of five stages (see Fig. 6 for overview) to be implemented in a roundtable setting with an independent external moderator skilled in conflict management and communication. Guiding questions are provided to frame discussions at each stage. Onus for convening this forum is on the project proponents and has to begin at the earliest (i.e., planning) stages of the project.

\subsection{Stage 1: Co-Selection}

Co-selection (see Fig. 1) is primarily aimed at democratizing representation by letting affected publics select their own representatives. This is particularly important for rural communities in developing countries where leadership structures are not formally institutionalized and ethnic minorities and women are underrepresented. Stakeholders are characterized by three broad categories: (affected) publics, government, and industry. ${ }^{6}$ Each category has a list of representation criteria that will give an indication of the individual's authority to speak on behalf of the larger community/organization (see Table I).

The number of representatives for each category should ideally be kept small to keep discussions manageable, with a greater proportion accorded to affected publics. To avoid the problem of hijacking by lobby groups with political agendas that may not be in the interest of the larger collective, NGOs or grass roots organizations that wish to represent the community must be nominated by residents. Priority should be given to participants who are nominated by the community directly affect by the project, and can be individuals who are already elected members of the community such as village chiefs, mayors, and council members. Representation by female members of the community should be emphasized if they are not already in positions of leadership. Information must be provided to the public in advance with sufficient time for dissemination and discussion within the community.

\subsection{Stage 2: Co-Design}

The objective of the co-design stage (see Fig. 2) is to facilitate the identification and alignment of goals and interests of project proponents and affected publics. The needs of the two groups may con-

\footnotetext{
${ }^{6}$ Note that state regulators are important stakeholders in deliberation, but their roles are often determined by legislation and not a subject of deliberation.
}

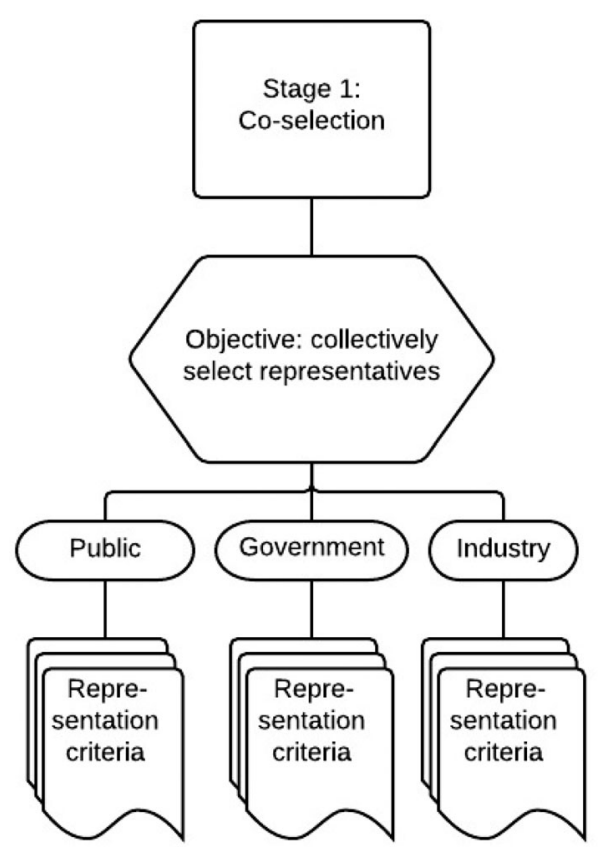

Fig. 1. Co-selection process.

flict in some areas but coincide in others. However, conflict tends to overshadow convergence in public debate. For example, the polarization of the nuclear debate in India (and beyond) between those who were either for or against nuclear power after the Fukushima disaster overshadowed the voices of moderation on both sides that called for more democratic process, scientific humility, and a broader focus on sustainable development and human security. ${ }^{(43)}$

This stage of deliberation, therefore, is aimed at avoiding simplistic "winner-loser," "for-against" dichotomies at the earliest stage of the project. This is done by scoping out the areas of converging interests, identifying synergies among all stakeholders, and integrating them at the design stage. The guiding questions for deliberation at this stage, therefore, can be formulated as:

1. What are the project goals/interests?

2. What are the affected communities' goals and interests?

These questions are aimed at opening discussions into what social goals the project serves, and not just the economic or technological objectives. If synergies are identified among stakeholder goals and interests, they then need to assess if new participants (e.g., external experts, university researchers, etc.) or resources need to be added to strengthen these 
Table I. Representation Criteria

\begin{tabular}{|c|c|c|}
\hline Affected Publics & Government & Industry \\
\hline $\begin{array}{l}\text { Is he/she a member of the affected } \\
\text { community? }\end{array}$ & $\begin{array}{l}\text { Is he/she based in the affected } \\
\text { zone/district/state or known to the } \\
\text { local community? }\end{array}$ & $\begin{array}{l}\text { Is he/she based at the site of local } \\
\text { operations? }\end{array}$ \\
\hline $\begin{array}{l}\text { Was he/she elected or nominated by the } \\
\text { community? }\end{array}$ & $\begin{array}{l}\text { Does he/she have good knowledge of the } \\
\text { local context - political, social, and } \\
\text { economic? }\end{array}$ & $\begin{array}{l}\text { Is he/she known to the local } \\
\text { community? }\end{array}$ \\
\hline $\begin{array}{l}\text { If the individual is a NGO representative } \\
\text { outside the affected community, has } \\
\text { he/she been working closely with the } \\
\text { community? }\end{array}$ & $\begin{array}{l}\text { Does he/she have authority to make } \\
\text { decisions in the local area? }\end{array}$ & $\begin{array}{l}\text { Does he/she have the authority to make } \\
\text { decisions in the local plant? }{ }^{8}\end{array}$ \\
\hline $\begin{array}{l}\text { Does the NGO representative have good } \\
\text { knowledge of the local context - } \\
\text { political, social, and economic? }\end{array}$ & $\begin{array}{l}\text { Does he/she have influence with the } \\
\text { bureaucracy? }\end{array}$ & $\begin{array}{l}\text { Does he/she have the authority to make } \\
\text { decisions in the parent organization? }\end{array}$ \\
\hline $\begin{array}{l}\text { Is there balanced } \\
\text { gender/ethnic/caste/class } \\
\text { representation? }\end{array}$ & Does he/she have political clout? & \\
\hline
\end{tabular}

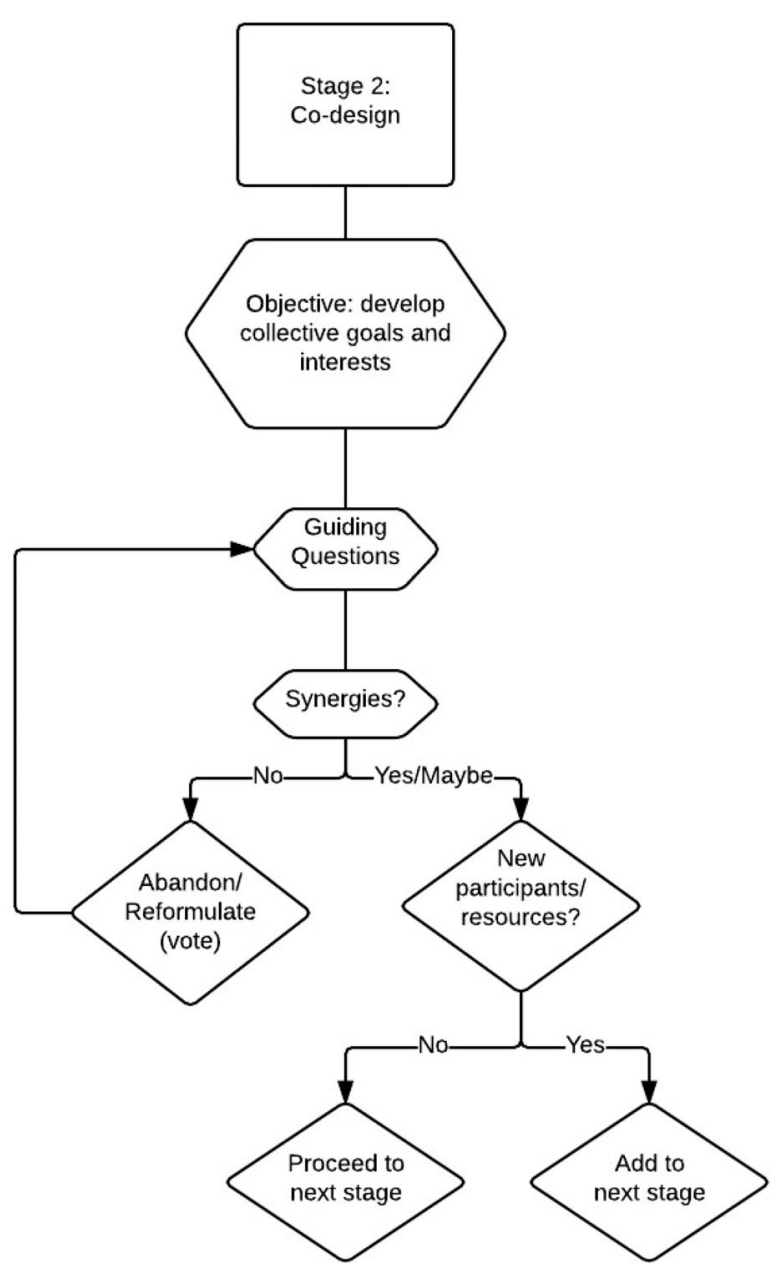

Fig. 2. Co-design process. synergies. If there are no areas of convergence, then a decision on whether to abandon the project or reformulate the project goals can be made through a vote at by representatives.

\subsection{Stage 3: Co-Definition}

Co-definition (see Fig. 3) is about integrating lay knowledge into the risk estimation, evaluation, and management process by providing a platform for knowledge to be produced collectively. The main objectives are to clarify what the problems are and, in the process, build trust by making uncertainties and unknowns a central topic of discussion while enlisting all participants in finding/proposing solutions. The guiding questions in this stage are thus formulated as:

1. What are the impacts from a technical perspective? What do the experts know?

2. What are the impacts from the affected publics' perspective? What do the publics know?

3. What are the unknowns?

This process allows a cross-examination of how the project impacts will affect the goals and interests identified in the preceding stage, and reassess how the larger collective pool of knowledge can help minimize impacts and maximize benefits. Additional experts or resources may need to be enlisted to fill information gaps, provide new insights, or propose alternatives. If all participants can agree on the set 


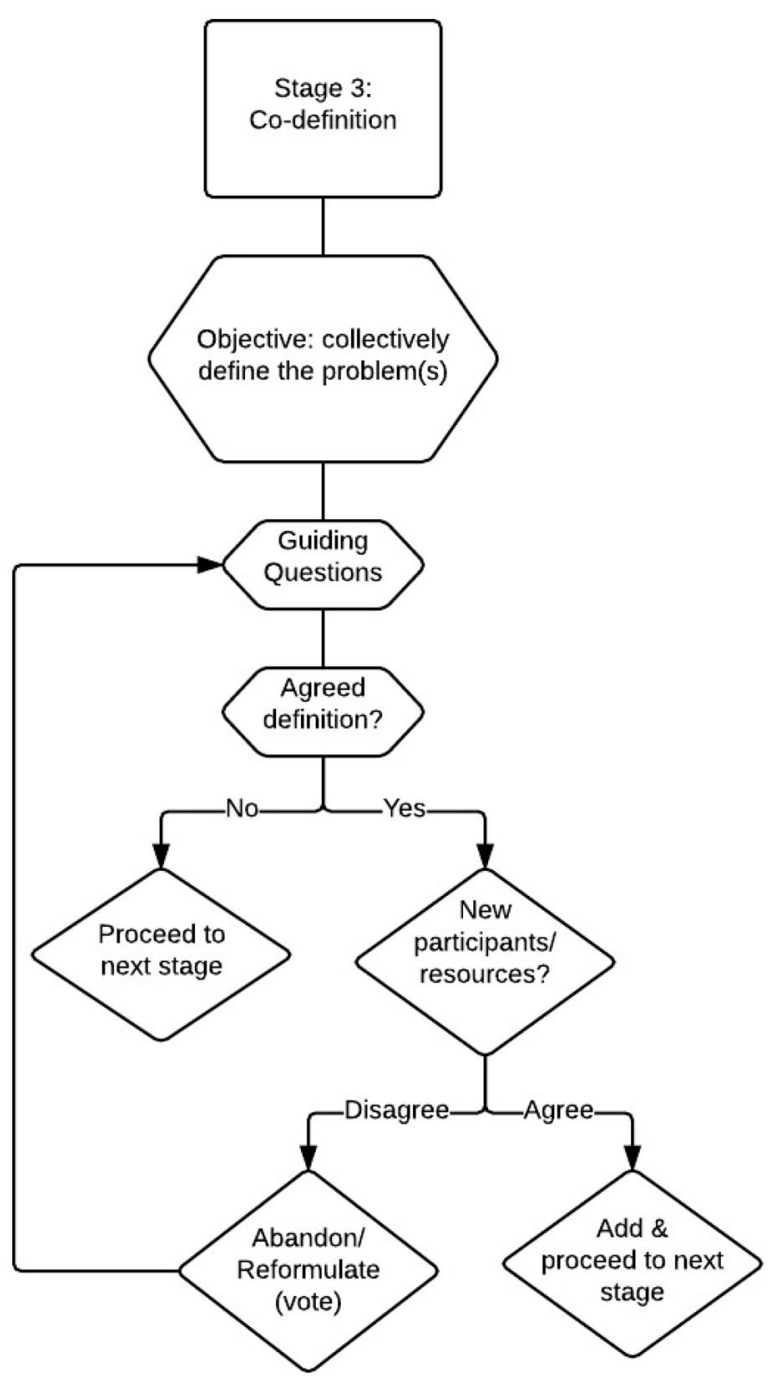

Fig. 3. Co-definition process.

of (problem) definitions and potential solutions, deliberation can proceed to the next stage of planning. If there is no agreement, participants have to decide whether to abandon the project or reevaluate the problems through a vote at by representatives.

\subsection{Stage 4: Co-Planning}

With an agreement on the set of definitions and potential solutions, co-planning (see Fig. 4) focuses on assigning areas of responsibility and resources to each stakeholder group. The guiding questions here are:

- What are the responsibilities of industry and the resources needed?
- What are the responsibilities of government and the resources needed?

- What are the responsibilities of affected publics and the resources needed?

With areas of responsibilities marked out, resources need to be matched to them. These fall under five general categories of human/social capital, financial, ecological, technology and infrastructure, and institutional (e.g., local legislation, licenses, government approvals, etc.). If there is agreement on the pool of resources needed, an assessment should be made about of whether new participants or resources need to be brought in to support action, or if existing resources or expertise can be shared among stakeholders. If there is conditional agreement, focus needs to be on what the conditions are; whether new resources or participants need to be enlisted; if existing resources can be shared; or if representatives need to make compromises. If there is no agreement, discussions need to turn towards possible compromises or new sources of capital or support.

Often, disagreements arise from the unequal distribution of resources. This stage of deliberation, therefore, is not just about expanding the pool of resources, but also redistributing and sharing existing ones. If the project goals, risk problems, and responsibilities have been collectively formulated, defined, and allocated in the preceding stages, stakeholders would have more shared interests at this stage and therefore have a greater stake in making the deliberation process a success. If, however, an agreement cannot be reached, then representatives have to vote on whether to abandon the project, renegotiate responsibilities and resource allocations, or return to stage three and reevaluate the definition/scope of the problem.

\subsection{Stage 5: Co-Regulation}

Co-regulation (see Fig. 5) is where shared responsibilities are translated into actionable items (roles) all stakeholder groups can take as the project is implemented so that there is shared accountability. This strengthens postimplementation accountability by involving affected publics in the entire lifecycle of the project, drawing on local expertise in the dayto-day management of risk, and building capacities in the process. The key components of this phase are the assignment of roles to respective stakeholder groups and the identification of deliverables, upon 


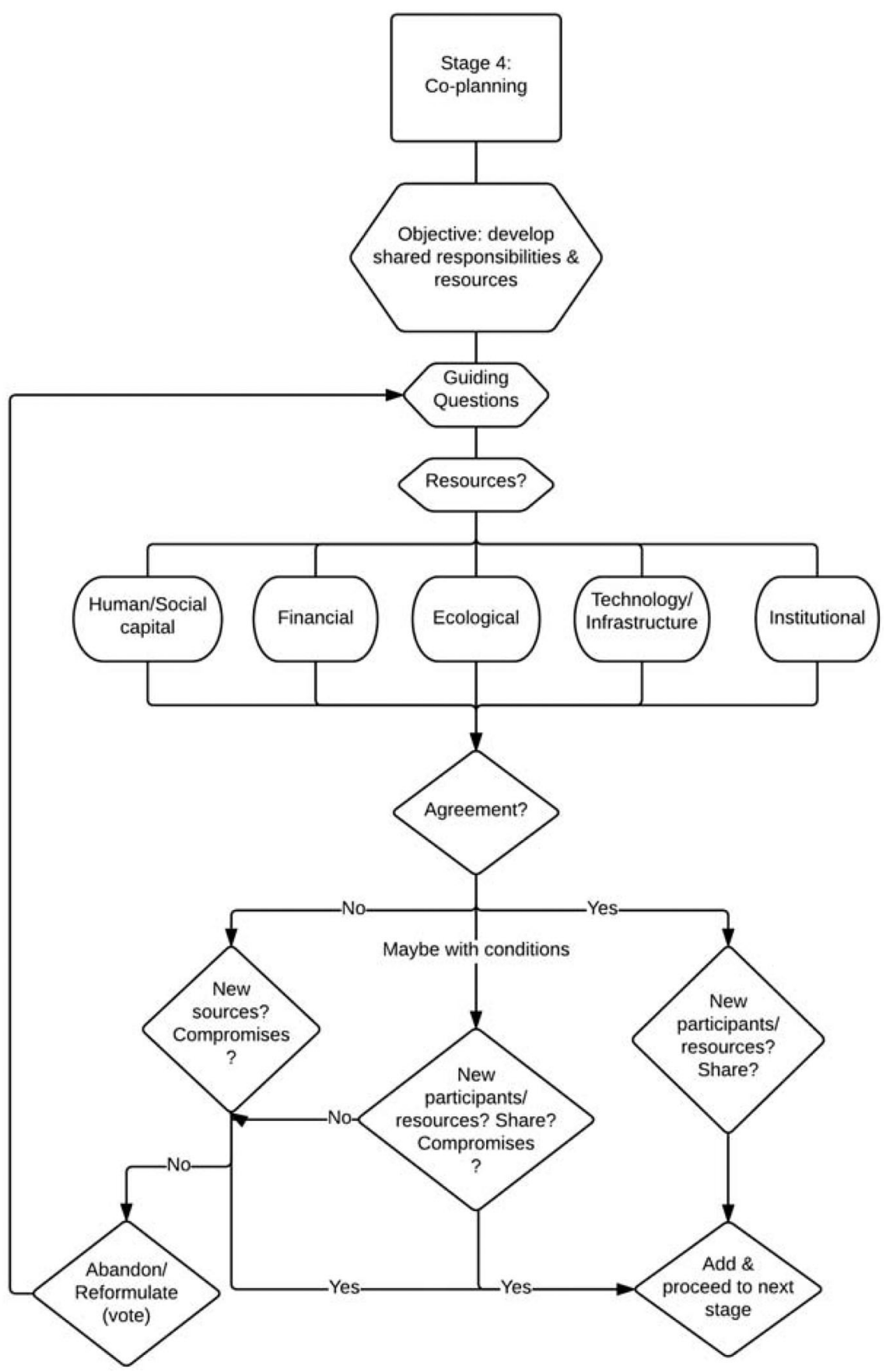

Fig. 4. Co-planning process.

which progress can be evaluated. The guiding questions at this stage are thus formulated as:

1. What are roles of each stakeholder group?

2. What should their deliverables be?

3. What capacities can be built in the process?
Based on the areas of responsibilities and the pool of resources agreed on in the preceding stage, the role of each stakeholder group is clarified and built into the project implementation plan. The emphasis here is for affected public representatives to identify areas that they can or would like to 


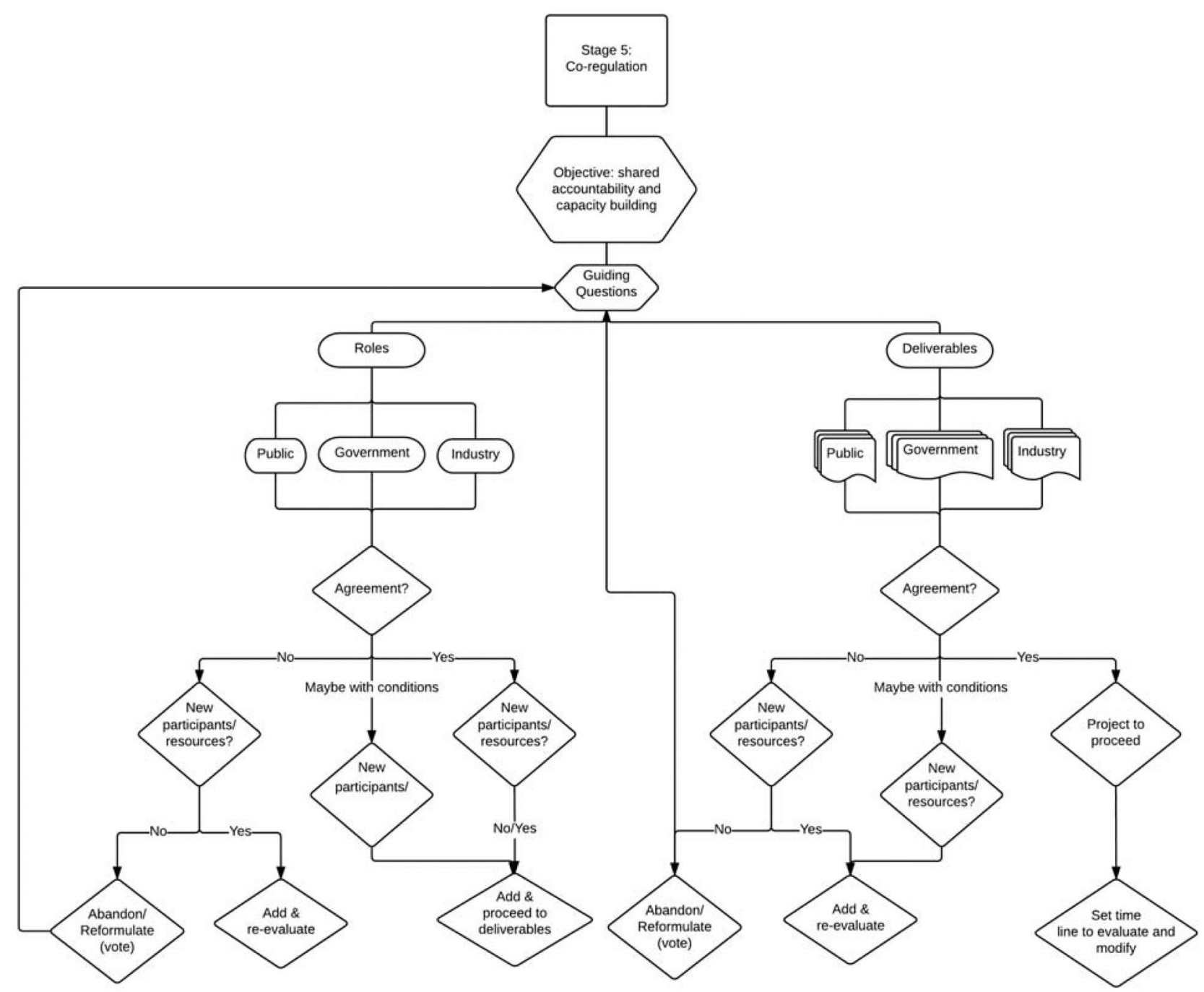

Fig. 5. Co-regulation process.

participate in. This is also where they can take up the role as third-party regulators in monitoring aspects of everyday operations that the corporation may not have the resources or manpower to do. Should affected publics lack the expertise, technology, or infrastructure to fulfil that role, government and industry stakeholders need to provide them with the skills and tools through workshops, equipment loans, rosters, direct lines of communication, etc. The benefits of this are twofold: firstly, it helps build capacity and creates shared ownership of physical components of the project; secondly, it mitigates situations of regulatory capture and poor safety culture that seep into the everyday operation of the project.

Laying out the deliverables is an important component as it provides a way to evaluate progress and establish accountability by institutionalizing transparency. Importantly, these roles and deliverables are not fixed. As the project progresses through the different stages of its lifecycle, they have to be reevaluated, the responsibilities and resources available will change, and the scope of problems will evolve. The network of relevant actors and resources will shift as the project progresses, when unexpected events occur, when governments change, when accumulated ecological effects are unleashed, or when the actions of one industry affect another. This reconfiguration of the risk landscape and the responses afforded by this framework are captured in (but not limited to) some possible scenarios presented in Table II. However, in the case that representatives cannot agree on the assignment of roles and 

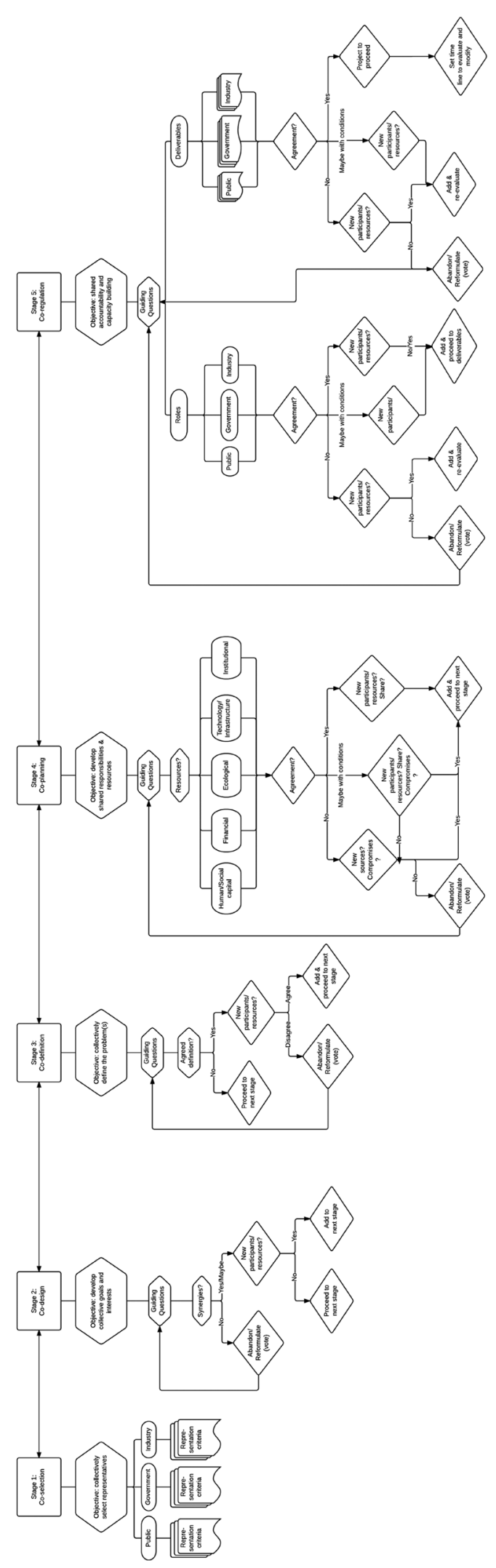

Table II. Scenarios of Changes in Risk Configuration

\begin{tabular}{lc}
\hline Scenario & \multicolumn{1}{c}{ Response } \\
\hline $\begin{array}{l}\text { Scenario 1: Unplanned events or } \\
\text { accidents cause impacts to }\end{array}$ & Return to stage 1. \\
spread to new geographical & \\
locations or have indirect & \\
consequences on another & \\
community, occupation group, & \\
or sector. & \\
$\begin{array}{l}\text { Scenario 2: Interests and goals of } \\
\text { some stakeholders have } \\
\text { changed. }\end{array}$ & Return to stage 2. \\
$\begin{array}{l}\text { Scenario 3: New knowledge or } \\
\text { information emerges, leading to } \\
\text { the realization that impacts or } \\
\text { risks are greater than previously } \\
\text { estimated. }\end{array}$ & $\begin{array}{c}\text { Return to stage 3, } \\
\text { potentially needing to } \\
\text { return to stage 1 if } \\
\text { new groups are } \\
\text { chario 4: Government policy } \\
\text { of subsidies, tighter regulations, } \\
\text { or legislation banning further } \\
\text { developments in the industry. }\end{array}$ \\
\hline
\end{tabular}

deliverables, a vote will have to be made on whether to abandon the project or renegotiate the set of arrangements.

In sum, this framework offers a set of procedures and mechanisms that can be used to start a deliberative process that provides direct participation of affected publics; mitigates hijacking by dominant/interest groups through co-selection of representatives; embeds public participation throughout the lifecycle of a project through co-design, coplanning, and co-regulation; and provides the mechanisms at each stage for new participants and resources to be enlisted (i.e., the reconfiguration of stakeholders), and for problems to be reformulated and modified.

\section{CHAllenges}

There are some conceptual and practical challenges to this hybrid risk governance framework. Conceptually, Callon and Latour have been heavily criticized for their agnostic approach to power ${ }^{(44)}$ and romanticizing the democratization of science and uncertainty. ${ }^{(45)}$ Indeed, Fuller (2010) contends that the "stuff of hybrid forums" is more applicable to groups looking to translate economic might into political might, while Gross (2011) points to Callon and colleagues' aversion to more sinister examples such as radical Islamist organizations or creationist movements, and the potential misuse of the versatile 
knowledge produced by hybrid forums. The public is also not always politically engaged or interested in participation. Distrust in institutions, class divisions, epistemic hierarchies, and the disjunction between future and present needs can cause public aversion to deliberative processes. ${ }^{(46)}$

This framework, however, circumvents some of these challenges by keeping the guiding questions at each stage open ended and oriented towards codefining problems rather than preselecting problems to be discussed. The representation criteria (Table I) is also designed to integrate those with poor economic and political resources into decision-making processes and translating their knowledge into activities and arrangements that can empower them. Nevertheless, the misuse of knowledge produced in such forums is a potential risk that needs to be captured in the reflexive components of the framework.

More practically, the framework also faces challenges in facilitating meaningful public participation because it hinges significantly on the communication and conflict resolution skills of the moderator. Industry and (in some cases) government experts may not consider lay specialist knowledge to be valuable to the process and reject attempts to collectively define problems and develop shared responsibilities, resources, and accountabilities. Furthermore, industry and/or government stakeholders may see this as a way to "greenwash" industrial projects or co-opt affected communities. Some established power brokers within the community or lobby groups may also consider these new arrangements as a threat to their positions of power and resist change.

But hazardous industries, not least nuclear power, are well acquainted with the heavy price of public resistance from the rippling effects of disasters and accidents, delayed operations, forced shutdowns, expensive and prolonged litigation, and added security risks. Added to that, clean-up costs and compensation are often so great that they far outweigh the cost of more participatory approaches to risk governance. It is therefore in the self-interest of project proponents to have meaningful public participation throughout the project lifecycle.

\section{CONCLUSION}

This article focused on the mutable nature of risk problems and acceptability in risk governance and sought to address it through the hybrid risk governance framework. This approach deepens the substantive contribution of affected publics through- out the lifecycle of a project. It also shifts the goals of public engagement and deliberation away from immutable notions of risk problems and acceptable risk-benefit tradeoffs towards a mutable conception of evolving risks and "work in progress acceptability." In doing so, affected publics become more than just passive providers of legitimacy to a project but active co-regulators and co-producers of knowledge. Deliberation goes beyond just minimizing risks but also building local capacities, expanding the scope of benefits, thereby increasing resilience.

The mutable nature of risk problems and its configuration of stakeholders are built into the process of deliberation by the reevaluation of relevant participants and resources at each stage, and the provision of pathways back to the different stages of deliberation when stakeholders fail to reach an agreement. This reflexive design reinforces the notion that disagreement does not mean the end of deliberation, but the reevaluation of the problem and rearrangement of resources and stakeholders.

The framework itself is, of course, imperfect and mutable. It will need modifications, elaboration, and improvements when applied to various (industry, political, cultural, ecological, etc.) contexts and as research on risk governance develops further. But it is a first step towards translating the conceptualization of risk and acceptability as mutable entities into a practicable set of arrangements that practitioners of risk governance can use to better navigate the complex and fluid landscape of risk problems and public acceptability.

\section{ACKNOWLEDGMENTS}

I would like to thank the two anonymous reviewers for their patience and constructive comments in the earlier drafts of this article. Special thanks also to Prof. Stewart Lockie for his encouragement, critical questions, and inspiration in writing this article.

\section{REFERENCES}

1. Obe M, Warnock E. Huge Tokyo rally protests nuclear restart. Wall Street Journal, 20121 July Asia. Available at: http://www.wsj.com/articles/ SB10001424052702303649504577496802810864704.

2. Associated Press. First Japanese nuclear power plant since Fukushima to resume operations. Guardian, 2014 7 Nov Japan. Available at: http://www.theguardian.com/ world/2014/nov/07/japanese-nuclear-power-plant-fukushimarestart.

3. Law J. Actor network theory and material semiotics. Pp. 141158 in Turner BS (ed). The New Blackwell Companion to Social Theory. West Sussex: Blackwell Publishing Ltd., 2009. 
4. Alcadipani R, Hassard J. Actor-network theory, organizations and critique: Towards a politics of organizing. Organization, 2010; 17(4):419-435.

5. Latour B. Science in Action. Cambridge, MA: Harvard University Press, 1987.

6. Aven T, Zio E. Foundational issues in risk assessment and risk management. Risk Analysis, 2014; 34(7):1164-1172.

7. Renn O. Risk Governance: Towards an Integrative Approach. IRGC White Paper No.1. Geneva: International Risk Governance Council, 2006.

8. Reason J. Safety paradoxes and safety culture. Injury Control and Safety Promotion, 2000; 7(1):3-14.

9. Schnaiberg A. The Environment: From Surplus to Scarcity. New York: Oxford University Press, 1980.

10. Weick KE. Sensemaking in Organizations. London: Sage Publications Ltd., 1995.

11. Hartz-Karp J, Pope J. Enhancing effectiveness through deliberative democracy. Pp. 253-272 in Vanclay F, Esteves AM (eds). New Directions in Social Impact Assessment: Conceptual and Methodological Advances. Northampton, MA: Edward Elgar Publishing, 2011.

12. Renn O, Klinke A. Complexity uncertainty and ambiguity in inclusive risk governance. Pp. 59-76 in Lockie S, Measham T (eds). Risk and Social Theory in Environmental Management. Collingwood: CSIRO Publishing, 2012.

13. Dryzek JS. Pragmatism and democracy: In search of deliberative publics. Journal of Speculative Philosophy, 2004; 18(1):72-79.

14. Dryzek J. Foundations of environmental political economy: The search for homo ecologicus? New Political Econonmy, 1996; 1(1):27-40.

15. Gunningham N, Kagan RA, Thornton D. Shades of Green: Business, Regulation, and Environment. California: Stanford University Press, 2003.

16. Gunningham N, Kagan RA, Thornton D. Social license and environmental protection: Why businesses go beyond compliance. Law and Society Inquiry 29, 2014; 1:307-341.

17. Braithwaite J. The essence of responsive regulation (Fasken Lecture). UBC Law Review, 2011; 44(3):475-520.

18. Lockie S, Measham T. Social perspectives on risk and uncertainty: Reconciling the spectacular and the mundane. Pp. 114 in Lockie S, Measham T (eds). Risk and Social Theory in Environmental Management. Collingwood: CSIRO Publishing, 2012.

19. Wynne B. May the sheep safely graze? A reflexive view of the expertlay knowledge divide. Pp. 44-83 in Lash S, Szerszynski B, Wynne B (eds). Risk, Environment and Modernity: Towards a new Ecology. London: Sage Publications Ltd, 1996.

20. Porter ME, Kramer MR. Shared value: How to reinvent capitalism and unleash a wave of innovation and growth. Havard Business Review, 2011, January-February, Pp. 3-17. Available at: http://www.fsg.org/Portals/0/ Uploads/Documents/PDF/Creating_Shared_Value.pdf.

21. Wong CML. Risk in the Making: A Case Study of Nuclear Power in India [dissertation]. Canberra: Australian National University, 2014.

22. IRGC. An Introduction to the IRGC Risk Governance Framework. Geneva: International Risk Governance Council, 2008. Available at: http://www.irgc.org/IMG/pdf/An introduction_to_the_IRGC_Risk_Governance_Framework. pdf.

23. Renn O, Klinke A, Asselt M. Coping with complexity, uncertainty and ambiguity in risk governance: A synthesis. Ambio, 2011; 40(2):231-246.

24. Renn O. Risk Governance: Coping with Uncertainty in a Complex World. New York: Earthscan Publishing, 2008.

25. Healy S. A "post foundational" interpretation of risk: Risk as "performance." Journal of Risk Research, 2004; 7(3):277-296.
26. Wynne B. Misunderstood misunderstanding: Social identities and public uptake of science. Public Understanding of Science, 1992; 1:281-304.

27. Lockie S. Deliberation and actor-networks: The "practical" implications of social theory for the assessment of large dams and other interventions. Society \& Natural Resources, 2007; 20(9):785-799.

28. Dryzek JS, Niemeyer S. Discursive representation. American Political Science Review, 2008; 102(4):481-493.

29. Becker HA, Vanclay F. The International Handbook of Social Impact Assessment. Northampton, MA: Edward Elgar Publications, 2003

30. O'Faircheallaigh C. Public participation and environmental impact assessment: Purposes, implications, and lessons for public policy making. Environmental Impact Assessment Review, 2009; 30(1):19-27.

31. Lofstedt R. Risk communication: Pitfalls and promises. European Review, 2003; 11(3):417-435.

32. Gunningham N, Grabosky PN, Sinclair D. Smart Regulation: Designing Environmental Policy. New York: Oxford University Press, 1998.

33. Gunningham N. Environment, self-regulation, and the chemical industry: Assessing responsible care. Law \& Policy, 1995; 17(1):57-109.

34. Rees JV. Hostages of Each Other: The Transformation of Nuclear Safety Since Three Mile Island. London: University of Chicago Press, 1994.

35. Elam M, Sundqvist G. Meddling in Swedish success in nuclear waste management. Environmental Politics, 2011; 20(2):246263.

36. Elam M, Sundqvist G. The Swedish KBS project: A last word in nuclear fuel safety prepares to conquer the world? Journal of Risk Research, 2009; 12(7-8):969-988.

37. Nielsen VL, Parker C. Testing responsive regulation in regulatory enforcement. Regulation \& Governance, 2009; 3(4):376399.

38. Wardrop A. Co-regulation, responsive regulation and the reform of Australia's retail electronic payment systems. Law in Context, 2014; 30(1):197-227.

39. Callon M, Lascoumes P, Barthe Y. Acting in an Uncertain World: An Essay on Technical Democracy. Cambridge, MA: MIT Press, 2011.

40. Jones BD. Bounded rationality. Annual Review of Political Science, 1999; 2(1):297-321.

41. Callon M, Rabeharisoa V. The growing engagement of emergent concerned groups in political and economic life: Lessons from the French Association of Neuromuscular Disease Patients. Science, Technology, \& Human Values, 2008; 33(2):230-261.

42. Callon M. The role of lay people in the production and dissemination of scientific knowledge. Science Technology \& Society, 1999; 4(1):81-94.

43. Wong CML. Organisational risk perception and transformations in India's nuclear establishment. Journal of Risk Research, 2014:1-18.

44. Fuller S. The new behemoth. Contemporary Sociology, 2010; 39(5):533-536.

45. Gross M. Review essay: Democratizing scientific uncertainty. Public Understanding of Science, 2011; 20(6):863864.

46. Tironi M. Disastrous publics: Counter-enactments in participatory experiments. Science, Technology \& Human Values, 2014:1-24.

47. The Economic Times. The new land acquisition act to come into effect from 2014. Economic Times, 2013, 16 Oct Economy. Available at: http://articles.economictimes. indiatimes.com/2013-10-16/news/43107324_1_monsoonsession-jairam-ramesh-new-land-acquisition-act. 